\title{
Viewpoint representation in journalistic crime narratives: An analysis of grammatical roles and referential expressions
}

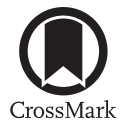

\author{
Kobie van Krieken ${ }^{*}$, José Sanders ${ }^{1}$, Hans Hoeken ${ }^{2}$
}

Centre for Language Studies, Radboud University Nijmegen, P.O. Box 9103, NL-6500 HD Nijmegen, The Netherlands

\begin{abstract}
This study examines how grammar and reference in journalistic narratives help to represent the viewpoints of eyewitnesses to shocking criminal acts. Grammatical roles of eyewitnesses and non-eyewitnesses and the expressions referring to them were analyzed in four journalistic narratives about different shocking events and compared to four non-narrative news reports about the same events. Results show that in the narratives, but not in the news reports, eyewitnesses appear more often in subject position of a clause than non-eyewitnesses. This indicates that in narratives, journalists choose eyewitnesses as the lens through which they narrate the events. Furthermore, eyewitnesses are more often referred to with pronouns than nouns, whereas non-eyewitnesses are more often referred to with nouns than pronouns. This indicates that eyewitnesses are cognitively highly accessible in news narratives and that their viewpoints are conceptually most proximate to the viewpoints of journalist and reader. It is argued that the strategic use of grammatical roles and referential expressions in journalistic crime narratives puts the reader in the position of a "mediated witness".
\end{abstract}

(c) 2014 Elsevier B.V. All rights reserved.

Keywords: Grammatical role; Referential expressions; Pronouns; Viewpoint representation; Journalistic narrative; Mediated witness

\section{Introduction}

Present-day journalism is characterized by a move from objective reporting toward subjective storytelling (Hartsock, 2007; Ytreberg, 2001). In the case of disturbing news events, such as homicides, terrorist attacks, and spree killings, journalistic narratives are written about the experiences of people involved in the events (Kitch, 2009; Wardle, 2006). These narratives differ in function from traditional news reports. Consider, for example, the first two paragraphs of a news report about a shooting at an elementary school in Newtown, Connecticut:

\section{Excerpt 1}

A man killed his mother at their home and then opened fire Friday inside an elementary school, massacring 26 people, including 20 children, as youngsters cowered in fear to the sound of gunshots reverberating through the building and screams echoing over the intercom.

\footnotetext{
* Corresponding author. Tel.: +31243612347.

E-mail addresses: k.vankrieken@let.ru.nl (K. van Krieken), j.sanders@let.ru.nl (J. Sanders), h.hoeken@let.ru.nl (H. Hoeken).

1 Tel.: +31243612802.

2 Tel.: +31243612884
} 
The 20-year-old killer, carrying at least two handguns, committed suicide at the school, bringing the death toll to 28 , authorities said.

(The Associated Press, 2012)

Evidently, the function of this news report is to provide the reader with newsworthy information about a recent event (Bell, 1991): The who, what, where, and when questions are answered in the very first sentence of the report. In journalistic narratives, on the other hand, the how question plays a central role. Compare excerpt 2 below, which is part of a journalistic narrative that covers the same shooting:

\section{Excerpt 2}

Library specialist Bev Bjorklund heard the noises and hustled about 15 students toward a storage closet in the library, which was filled with computer servers. "Hold hands. Be quiet," she told the kids. They looked back at her, confused. One child wondered if pots and pans were clanging. Another thought he heard firecrackers. Another worried an animal was coming to the door.

They were children in a place built for children, and Bjorklund didn't know how to answer them. She told them to close their eyes and to keep quiet. She helped move an old bookshelf in front of the door to act as a makeshift barricade. She wondered: How do you explain unimaginable horror to the most innocent?

(The Washington Post, 2012)

This excerpt displays several characteristics that deviate from the standard way of reporting in news reports, but that are typical for news narratives: The events are chronologically ordered, situated in a detailed setting, and described from the perspective of an eyewitness.

Journalistic narratives about shocking crimes are thought to "invite" readers to become mediated witnesses, a phenomenological experience in which readers empathize with eyewitnesses and victims of a criminal act and vicariously experience the crime themselves (Peelo, 2006). This function is important as it provides the audience with the opportunity to experience what it must have been like to be present at the events. For this effect to occur, it requires readers to take the viewpoint of actual witnesses to the event. Linguistic choices help creating these viewpoints: Selecting either a pronoun or a full noun to refer to a person as well as choice of word order guides the interplay between the viewpoints of journalist, reader, and eyewitness (Hendriks et al., 2012; Langacker, 1987, 1991; Van Hoek, 2007). The present study examines how grammatical roles and referential expressions are used in journalistic narratives to describe shocking news events from the viewpoints of eyewitnesses, thereby aiming to turn readers into mediated witnesses who experience these events up close and personal.

\subsection{Linguistic approaches to viewpoint representation in journalism}

Compared to authors of fictional novels on criminal acts, journalists are highly limited in their options to represent different viewpoints. In fiction, the interplay between multiple viewpoints (i.e., viewpoints of narrator and character(s)) is often complex, with processes of viewpoint shifting and blending affecting the reader's position relative to the narrative events and characters (Dancygier, 2012a). For instance, a mystery novel can describe a murder case from the viewpoint of the detective investigating the case, inviting readers to take the viewpoint of the detective and challenging them to solve the case. Alternatively, that same murder case can be described from the viewpoint of the murderer, inviting readers to take the viewpoint of the murderer and pulling them into the mind of a sociopath. Another possibility could be that the murder case is described partly from the detective's viewpoint and partly from the murderer's viewpoint. These different types of viewpoint configurations are guided by linguistic choices, with different linguistic categories related to different aspects of viewpoint. For example, verbs of seeing signal spatial viewpoint, modal verbs signal epistemic viewpoint, and thought representations signal psychological viewpoint. These and other grammatical and lexical choices provide the narrator of fiction with countless possibilities to represent narrative events and situations from a specific or multiple points of view.

In journalistic narratives, by contrast, some of these viewpoint representation strategies are not applicable because of the genre conventions. The objectivity norm dictates that journalistic articles should provide an accurate and neutral account of what happened in reality (e.g., Schudson, 2001). In line with this norm, news events are to be described from an "objective" viewpoint. Journalistic articles that represent news events from the viewpoints of people involved are thus at odds with the objectivity norm. In addition, accessing and representing the inner side of persons' minds is not allowed for journalists - as opposed to writers of fiction. Such "strong" perspectivization techniques are incompatible with the requirements of the news genre, which imposes restrictions on the possibilities to represent news events from the viewpoints of subjective others. However, more subtle strategies can be used to represent viewpoints in an implicit 
manner (Sanders and Redeker, 1993). The inflexible conventions of Western-world journalism make it relevant to study how journalists use language to represent the viewpoints of others, without violating the norms of their genre.

Thus far, linguistic analyses of journalistic texts have largely been restricted to two aspects of viewpoint representation: The representation of emotions and the representation of speech and thought. Studies examining emotions have employed Appraisal Theory (Martin and Rose, 2003; Martin and White, 2005) to uncover how journalists intersperse their writings with expressions of affect and evaluation on part of persons involved in news events (Stenvall, 2008; WahlJorgensen, 2013a,b). Through the use of such expressions, journalists encourage the reader to share the emotions of these persons. These studies have mainly provided insight into the representation of viewpoint as it resides in the use of lexical items (e.g., angry, relieved) to denote the emotional states of people affected by news events.

On a different dimension, the representation of speech and thought provides another range of possibilities for journalists to give expression to the viewpoints of others. Choices between representation mode, i.e., direct (quotation), indirect (paraphrase), or free indirect (represented dialog or stream of consciousness) signify the degree to which the journalist merges another person's viewpoint with his own viewpoint. By using the direct representation mode, the journalist remains at a distance from the viewpoint of the quoted person, whereas the use of indirect and free indirect representation mode establishes - to different degrees - a fusion of this person's viewpoint and the journalist's viewpoint (Sanders, 2010). A fourth, non-canonical representation mode which can be found in journalistic discourse is distancing indirect speech or thought (Vandelanotte, 2004). Excerpt 1 from The Associated Press provides an example of distancing indirect speech: The 20-year old killer, carrying at least two handguns, committed suicide at the school, bringing the death toll to 28, authorities said. Note that the absence of quotation marks and the sentence-final position of the reporting clause prioritize the informative value of what was said and de-emphasize the importance of who was responsible for what was said. As such, this representation mode "render[s] a 'voice' distinct from the current speaker's, albeit in an echoic way" (Vandelanotte, 2004: 573).

Linguistic elements that represent persons' emotions and speech or thought signify whose voices sound and resound through the journalist's voice. On a more fundamental level, linguistic elements also signify who of the persons involved in the narrative serves as the lens of narration, i.e., from whose position a narrative scene is viewed. Important indicators of the lens of narration are grammatical roles and referential expressions (Langacker, 1987, 1991; Van Hoek, 2007). In studying the representation of viewpoint in journalistic narratives, an analysis of these linguistic categories is important as they not only reveal from whose viewpoint the journalist narrates the news events, but also signify the proximity between the viewpoints of journalist, news actor, and reader. These categories will be discussed below.

\subsection{Grammatical roles, referential expressions, and viewpoint representation}

When introducing and further referring to a person (from here on: protagonist), journalists can situate this protagonist as closer to or further away from their own perceptual and cognitive perspective, in short: their viewpoint. The linguistic instruments to regulate a protagonist's proximity are the grammatical role of this protagonist on the one hand, and the type of expression used to refer to this protagonist on the other.

\subsubsection{Grammatical roles}

Since the grammatical subject is the dominant position of a clause, the protagonist who fulfills the role of subject is the most prominent participant in that clause (Langacker, 1991: 321). More specifically, the subject of a clause serves as the vantage point of narration as it indicates the position from which a particular scene is viewed (cf. Langacker, 1987: 123). This can be illustrated with a simple example. In the sentence "John kisses Mary on the cheek", the scene is described from John's point of view. In the passive equivalent of that sentence, "Mary is kissed on the cheek by John", Mary takes over the role of subject and the scene is now described from her point of view. Metaphorically speaking, the camera is located near John in the first sentence and near Mary in the second sentence (Kuno, 1987). A grammatical subject can thus be seen as the lens through which the journalist narrates the events and, by consequence, through which the reader perceives them (Van Hoek, 2007). The viewpoint of a protagonist with subject status is therefore conceptually most proximate to both the journalist's and the reader's viewpoints.

In excerpt 2, for instance, a common clause structure is one in which the library specialist appears in subject position and the children in object position (e.g., "Bjorklund didn't know how to answer them", "She told them to close their eyes and to keep quiet"). The grammatical structures of these clauses mark the prominence of the library specialist and indicate that the scene is viewed from this person's viewpoint. Her viewpoint is thus most proximate to the viewpoints of journalist and reader.

\subsubsection{Referential expressions}

During the description of events, the narrative's protagonists will be referred to repeatedly. Referential expressions are also indications for the proximity of these protagonist's viewpoints, which may change during the narrative. Referential expressions signify the cognitive status of the protagonist, i.e., the degree to which the protagonist is accessible and active 
in short-term memory (Ariel, 1988). Pronominal references mark high accessibility, indicating that the protagonist is the focus of attention, whereas nominal references mark low accessibility, indicating that the protagonist is less prominent (Ariel, 1988; Gundel et al., 1993). The accessibility of a protagonist is regulated by several discourse factors, such as the amount of text between two references to the protagonist and the number of competing referents (Ariel, 1988, 1990; Clancy, 1980). These factors thus play a role in determining whether a noun or a pronoun is most appropriate to refer to a protagonist.

However, choices of referential expressions are not solely guided by factors related to discourse structure. Fox (1987), for instance, discusses examples of nominal references used in a context in which a pronoun could have been used without causing ambiguity. In these instances, nominal references are used to express disapproval or disagreement with the referent, creating distance between the narrator and the referent. Choice of referential expression can thus be guided by the wish to express nuances as to one's attitude toward the referent. Drawing on similar observations, Van Hoek (1997, 2007) discusses referential expressions in terms of conceptual distance: Pronouns position the protagonist closer to the narrator and reader while nouns set them further apart. Importantly, conceptual distance is associated with viewpoint, such that a pronoun not only signals the conceptual proximity of a protagonist, but also indicates that a scene is viewed from that protagonist's viewpoint (Van Hoek, 2003, 2007).

In excerpt 2, for example, the library specialist is mostly referred to with a pronoun (e.g., "she told", "she helped", "she wondered"). This marks the cognitive accessibility and conceptual proximity of this protagonist and signals that the events are described from her viewpoint. For comparison, in the part of the news report given in excerpt 1 , only nominal referential expressions are used (e.g., "a man", "youngsters"). These expressions signify the conceptual distance between journalist and protagonists.

\subsubsection{Hypotheses}

Summarizing, journalistic narratives about shocking news events attempt to transform readers into mediated witnesses to these events, an experience in which they empathize with actual eyewitnesses and vicariously observe the events from these persons' viewpoints (Peelo, 2006). In representing viewpoints, journalists are bounded by news conventions which prohibit them from using techniques used by authors of fiction. However, choice of grammatical roles and referential expressions steer readers' conceptualization of the news events without being at odds with these conventions. Given that the grammatical role of a protagonist is indicative of the vantage point of narration (Langacker, 1991; Van Hoek, 2007), the following hypothesis can be formulated:

Hypothesis 1. In journalistic narratives, eyewitnesses to shocking news events appear more often in the subject position of a clause than non-eyewitnesses.

In addition, referential expressions are indicative of the cognitive accessibility of a protagonist and the proximity between the viewpoints of protagonist, journalist, and reader (Ariel, 1988; Van Hoek, 2003, 2007). This leads to the following hypothesis about the referential expressions used in journalistic narratives to refer to protagonists appearing in subject position:

Hypothesis 2. In journalistic narratives, eyewitnesses to shocking news events are more often referred to with a pronoun than a noun, whereas non-eyewitnesses are more often referred to with a noun than a pronoun.

These hypotheses were tested in an analysis of four journalistic narratives about different shocking criminal acts. To contrast the findings for these journalistic narratives, four journalistic news reports about these same events were analyzed as well.

\section{Study}

\subsection{Materials}

Two American and two Dutch journalistic narratives about (different) shocking criminal acts were selected. An article was classified as a narrative if it displayed on ore more of the following characteristics (cf. Johnston and Graham, 2012): an anecdotal (feature) lead, the setting of a scene, detailed descriptions. The American narratives were taken from The Washington Post (WP) and covered two of the deadliest shootings in the history of the United States: A spree killing on the Virginia Tech campus in $2007^{3}$ and a shooting at a movie theater in Aurora, Colorado in 2012. During the Virginia Tech massacre, 33 people were killed (including the perpetrator) and 17 were wounded. During the Aurora shooting, 12 people

\footnotetext{
${ }^{3}$ This article ("That was the desk I chose to die under") is a long narrative which covers the entire day of the shooting with elaborate accounts of its preamble and aftermath. For the purpose of this study, only the section that describes the actual attacks on the students and teachers on the Virginia Tech campus ("Popping sounds in the hallway") was included in the analysis.
} 
Table 1

Overview of materials and number of words per article.

\begin{tabular}{|c|c|c|c|c|c|c|c|}
\hline & \multicolumn{3}{|c|}{ American articles } & \multicolumn{3}{|c|}{ Dutch articles } & \multirow[t]{2}{*}{ Total } \\
\hline & Aurora & Virginia & Total & Apeldoorn & Alphen & Total & \\
\hline Narrative (WP/NRC) & 1552 & 1538 & 3090 & 628 & 1238 & 1866 & 4956 \\
\hline News report (AP/ANP) & 945 & 933 & 1878 & 488 & 228 & 716 & 2594 \\
\hline Total words & 2497 & 2471 & 4968 & 1116 & 1466 & 2582 & 7550 \\
\hline
\end{tabular}

were killed and 70 were wounded. The Dutch narratives were taken from the newspaper NRC Handelsblad (NRC) and covered two of the deadliest attacks in the history of the Netherlands: An attack on the Dutch Royal Family in Apeldoorn in 2009 and a spree killing in a shopping mall in Alphen aan den Rijn in 2011. In the attack on the Royal Family, 8 people died (including the perpetrator) and 10 were wounded. During the spree killing in the shopping mall, 7 people were killed (including the perpetrator) and 17 were wounded. The four cases are similar in impact and, most importantly, all four criminal acts were committed in public places with many eyewitnesses.

For each case, a news report from a news agency was selected to compare the use of grammatical roles and referential expressions in journalistic narratives with the use of grammatical roles and referential expressions in nonnarrative news reports. This comparison was made in order to determine whether the results for grammar and reference use would be specific to news narratives or whether they would be genre-independent. News reports about the American cases were retrieved from news agency The Associated Press (AP). News reports about the Dutch cases were retrieved from news agency Algemeen Nederlands Persbureau (ANP). An overview of the materials and the number of words per article can be found in Table 1.

\subsection{Analysis}

An analysis of the grammatical subjects and their referential expressions found throughout the narratives and the news reports was performed to assess the prominence of the various protagonists' viewpoints and their proximity to the narrator's viewpoint. Since the primary interest of this study is the representation of viewpoints of eyewitnesses to shocking news events, a division was made between the persons who evidently fulfill the role of eyewitness in the articles and persons who fulfill a different role. Individuals who witnessed (saw and/or heard) the act from up close and could be identified as such based on the article were labeled as eyewitness. Non-eyewitnesses were labeled as victim, perpetrator, police, authorities, or other (groups of) person(s).

Objects of the analysis were all expressions in subject position of a clause referring to persons. The referential expressions of all subjects were coded as either pronominal or nominal (occurrences of indefinite noun phrases, definite noun phrases, nouns with a null determiner, and proper names were added up). The results were analyzed using chisquared tests.

\section{Findings}

Table 2 shows the results of the analysis of referential expressions in the journalistic narratives and news reports. Whereas 437 referential expressions were used in the journalistic narratives ( 1 per 11.3 words), the news reports contained 167 referential expressions ( 1 per 15.5 words). The higher density of expressions referring to persons in the

Table 2

Distribution of pronominal and nominal referential expressions in subject position of a clause in journalistic narratives and news reports.

\begin{tabular}{|c|c|c|c|c|c|c|c|}
\hline \multirow[t]{2}{*}{ Referential expression } & \multicolumn{7}{|l|}{ Referent } \\
\hline & Eyewitness & Victim & Perpetrator & Police & Authorities & Other(s) & Total \\
\hline \multicolumn{8}{|l|}{ Narrative } \\
\hline Pronoun & $131(63.6 \%)$ & $17(34.7 \%)$ & $41(47.1 \%)$ & $9(25.7 \%)$ & $1(8.3 \%)$ & $21(43.8 \%)$ & $220(53.8 \%)$ \\
\hline Noun & $75(36.4 \%)$ & $32(65.3 \%)$ & $46(52.9 \%)$ & $26(74.3 \%)$ & $11(91.7 \%)$ & $27(56.3 \%)$ & $217(46.2 \%)$ \\
\hline Total & $206(47.1 \%)$ & $49(11.2 \%)$ & $87(19.9 \%)$ & $35(8.0 \%)$ & $12(2.7 \%)$ & $48(10.9 \%)$ & $437(100 \%)$ \\
\hline \multicolumn{8}{|l|}{ News report } \\
\hline Pronoun & $17(44.7 \%)$ & $4(14.3 \%)$ & $8(29.6 \%)$ & $2(9.1 \%)$ & $5(20.8 \%)$ & $8(28.6 \%)$ & $44(26.3 \%)$ \\
\hline Noun & $21(55.3 \%)$ & $24(85.7 \%)$ & $19(70.4 \%)$ & $20(90.9 \%)$ & $19(79.2 \%)$ & $20(71.4 \%)$ & $123(73.7 \%)$ \\
\hline Total & 38 (22.8\%) & $28(16.8 \%)$ & 27 (16.2\%) & $22(13.2 \%)$ & 24 (14.4\%) & $28(16.8 \%)$ & 167 (100\%) \\
\hline
\end{tabular}


narratives compared to the hard news reports points toward a greater prominence of persons in the narratives. Table 2 furthermore shows that pronominal referential expressions and nominal referential expressions were used equally often in the narratives, whereas in the news reports, nominal referential expressions were employed much more frequently. This seems to indicate that the news reports were more distant by nature than the narratives.

As predicted by hypothesis 1 , eyewitnesses appeared more often in the subject position of a clause in the news narratives than non-eyewitnesses $\left(\chi^{2}(5)=332.96, p<.001\right.$ ). Pairwise comparisons (Marascuilo, 1966) revealed that the eyewitnesses appeared significantly more often in subject position $(47.1 \%)$ than the victims $(11.2 \%)$, the perpetrator $(19.9 \%)$, the police $(8.0 \%)$, the authorities $(2.7 \%)$, and the other (groups of) persons $(10.9 \%)$, respectively (see the appendix for all pairwise comparisons).

In the news reports, on the other hand, the relative occurrences of eyewitnesses (22.8\%) and non-eyewitnesses in subject position (ranging between 14.4 and $16.8 \%$ ) did not differ significantly from one another $\left(\chi^{2}(5)=5.49, p=.359\right.$ ). Together, these results demonstrate that in journalistic narratives, but not in hard news reports, the eyewitnesses appeared more often in subject position of a clause than the non-eyewitnesses. The results thus provide strong support for hypothesis 1 .

As predicted by hypothesis 2, eyewitnesses in journalistic narratives were more often referred to with a pronoun $(63.6 \%)$ than a noun $(36.4 \%)$, whereas non-eyewitnesses were more often referred to with a noun $(61.5 \%)$ than a pronoun $(38.5 \%){ }^{4}$ The difference in expressions used in journalistic narratives to refer to eyewitnesses and expressions used to refer to non-eyewitnesses was highly significant $\left(\chi^{2}(1)=27.36, p<.001\right)$. The standardized residuals indicated that the number of pronouns used to refer to eyewitnesses was significantly higher $(p<.01)$ than the number that would be expected if there was no association between type of protagonist (eyewitness/non-eyewitness) and type of reference (pronoun/noun). The number of nouns referring to eyewitnesses was significantly lower than would be expected $(p<.01)$. For the use of pronouns and nouns referring to non-eyewitnesses, the exact opposite pattern was obtained $(p$ 's $<.05)$.

In the news reports, both the eyewitnesses and the non-eyewitnesses were more often referred to with nouns than pronouns $(55.3 \%$ versus $44.7 \%$ for the eyewitnesses; $79.1 \%$ versus $20.9 \%$ for the non-eyewitnesses). An unexpected significant difference was found, however $\left(\chi^{2}(1)=8.57, p<.01\right)$. The standardized residuals indicated that the number of pronouns used to refer to eyewitnesses was significantly higher than the number that would be expected if there was no association between type of protagonist and type of reference $(p<.05)$. The number of nouns referring to eyewitnesses did not differ from the expected number $(p>.05)$. The numbers of nouns and pronouns referring to the non-eyewitnesses did not differ from the expected numbers either ( $p$ 's $>.05$ ).

These results show that news narratives as well as news reports use relatively many pronouns to refer to eyewitnesses. This seems to indicate that in both genres, the viewpoints of eyewitnesses are conceptually proximate and that the events are related through their viewpoints. However, it appeared that one of the four news reports - the AP news report about a shooting in a movie theater - accounted for more than $88 \%$ of the pronominal references to eyewitnesses in these reports. A comparison between this report and the narratives reveals some essential differences in the way pronouns are used. Consider the following excerpt from this report:

\section{Excerpt 3}

Benjamin Fernandez, 30, told the Post that he heard a series of explosions. He said that people ran from the theater and there were gunshots as police shouted "get down!" Fernandez said he saw people falling, including one young girl.

In this fragment, three of the five references made to the eyewitness are pronominal. Two of these pronominal references appear in subordinate clauses. In these subordinate clauses, nominal references would be highly anomalous because the main clauses already contain nominal references to the eyewitness (e.g., Ariel, 1988). Following this line of thought, the use of pronouns in this news report thus appears to be determined by the clause structures rather than the journalist's intention to describe the events from the eyewitness's viewpoint. Note also that each sentence contains a reporting verb and reported speech, which signals that the eyewitness's primary role is that of a news source.

Now compare the following excerpt from the NRC narrative about a spree killing in a shopping mall:

\section{Excerpt 4}

An older man escapes in front of him [the gunman] and ducks into the Hubo. He was recently with his granddaughter, but he has now lost her. Quickly he gets up again. He sees a man and a woman lying on the ground, bathed in blood. He sees fear, panic. He finds his granddaughter again.

\footnotetext{
${ }^{4}$ In the analyses performed to test hypothesis 2 , the different groups of non-eyewitnesses were taken together in order to avoid low cell frequencies.
} 
After the eyewitness is introduced by an indefinite noun phrase in the first sentence, he is referred to with a pronoun six times in five sentences. This marks the high accessibility and conceptual proximity of the eyewitness. Importantly, at least one or two of the pronominal references could be substituted with nominal references without causing abnormalities or ungrammaticalities, for example: An older man escapes in front of him [the gunman] and ducks into the Hubo. He was recently with his granddaughter, but he has now lost her. Quickly the man gets up again. Hence, in this narrative, the use of pronouns does not appear to be dictated by clause structure or discourse structure; rather, pronouns are used strategically to situate readers close to the eyewitness and to invite them to look at the shooting from his viewpoint. This effect becomes even stronger through the short, staccato sentences and the verbs of perception, which add to the cinematic portrayal of events. The scene unfolds as if it were part of a movie in which the camera angle is located over the shoulder of the eyewitness and the viewers can only see what he sees. Note also that the eyewitness is not referred to by his name and that no speech is reported, which signifies that his primary role is that of a narrative character rather than that of a news source.

In sum, although both narratives and reports use relatively many pronouns to refer to eyewitnesses, only narratives appear to use pronouns as a strategy to describe news events from the viewpoints of eyewitnesses. To further substantiate this interpretation, some alternative explanations for the distribution of pronouns and nouns in the news narratives should also be considered. One alternative explanation could be that eyewitnesses in news narratives are a homogeneous group of central characters, and therefore more likely to be referred to with pronouns, whereas noneyewitnesses are a heterogeneous group of peripheral characters, requiring nominal referential expressions in order to avoid ambiguity (cf. Ariel, 1988, 1990; Clancy, 1980). A closer look at the protagonists of the narratives can shed light on the plausibility of this alternative explanation. Consider, for example, the following excerpt from the NRC narrative about the attack on the Dutch Royal Family:

\section{Excerpt 5}

Ria and Harry van Franke were standing ten meters away from the place where the car had driven through the fences. The scene of the accident is blocked off.

They are upset. Full of emotion, they tell how they saw people flying through the air, how they saw wounded children lying on the ground. They are convinced it was a deliberate act.

Willem-Jan Mulder was standing near the incident and says that he saw three policemen and three children fly through the air when the car drove into the crowd.

This excerpt shows how multiple viewpoints are involved in the narratives (see Van Krieken et al., submitted for publication-a for in-depth analyses of viewpoint multiplicity in news narratives). Crucially, different eyewitnesses are introduced shortly after each other; a clear topic is absent. In fact, none of the narratives analyzed in this study revolves around one or a few central eyewitnesses who can be considered to be the global topic(s) of the story; instead, many eyewitnesses (as well as non-eyewitnesses) are introduced who serve as consecutive local topics. It thus appears that neither topic-comment structure nor a supposed difference in homogeneity can account for the difference in expressions used to refer to eyewitnesses and non-eyewitnesses.

One could argue that the prominence of eyewitnesses, as indicated by the higher number of total references to eyewitnesses compared to non-eyewitnesses (cf. hypothesis 1), is responsible for the difference in pronominal and nominal references between eyewitnesses and non-eyewitnesses. Specifically, a protagonist who is referred to frequently is likely to be referred to with pronouns more often than nouns, while a protagonist who is referred to less frequently is likely to be referred to with nouns more often than pronouns. To examine this alternative explanation, an additional two-step analysis was performed. In the first step, it was examined how many individual eyewitnesses and non-eyewitnesses, introduced by a proper name or an indefinite noun phrase, were referred to in the news narratives. ${ }^{5} \mathrm{~A}$ narrative contained on average references to six individual eyewitnesses and eight individual non-eyewitnesses. This corroborates the observation made above: the eyewitnesses cannot be considered to be "more homogeneous" than the noneyewitnesses. Both eyewitnesses and non-eyewitnesses thus require nominal referential expressions in order to avoid ambiguity, which means that risk of ambiguity cannot explain for the difference in pronoun use between eyewitnesses and non-eyewitnesses.

In the second step, the expressions referring to individual eyewitnesses and non-eyewitnesses were analyzed. The results are listed in Table 3.

\footnotetext{
${ }^{5}$ Hence, generic references to eyewitnesses and non-eyewitnesses (e.g., "bystanders", "people", "the first responding officers") were excluded from this analysis.
} 
Table 3

Distribution of pronouns and nouns referring to individual eyewitnesses, individual non-eyewitnesses, and perpetrators in journalistic narratives.

\begin{tabular}{llll}
\hline & Individual eyewitness & Individual non-eyewitness & Perpetrator \\
\hline$N$ subject position & 7.46 & 4.53 & 21.75 \\
Pronoun & $5.13(68.72 \%)$ & $2.25(49.66 \%)$ & $11.25(51.72 \%)$ \\
Noun & $2.33(31.28 \%)$ & $2.28(50.34 \%)$ & $10.50(48.28 \%)$ \\
\hline
\end{tabular}

Table 3 shows that an individual eyewitnesses was on average referred to 7.46 times, and in almost $69 \%$ of the occurrences with a pronoun. An individual non-eyewitness was on average referred to 4.53 times, but only in less than $50 \%$ of the occurrences with a pronoun. That this difference in pronoun use was not caused by the prominence of the eyewitnesses (as indicated by the higher total number of references to an individual eyewitness compared to an individual non-eyewitness), follows from an analysis of the way in which reference is made to the perpetrators only. A perpetrator was on average referred to 21 times (which is three times as many as an individual eyewitness), ${ }^{6}$ but almost equally often with a noun as a pronoun. This analysis thus demonstrates that there is no clear linear relationship between the total number of references to a protagonist and the relative number of pronominal (versus nominal) references to this protagonist. Hence, the difference in pronominal and nominal references between eyewitnesses and non-eyewitnesses cannot be explained by a difference in prominence, but rather by a strategic use attributed to the function of news narratives.

\section{Conclusion}

The results of this study reveal how choices of grammatical roles and referential expressions in journalistic narratives help to represent the viewpoints of eyewitnesses to shocking criminal acts in two ways. First, eyewitnesses are placed more often in subject position of a clause than non-eyewitnesses. Eyewitnesses are thus the most prominent participants in the narrative; they serve as the lens through which journalists narrate the news events and, by consequence, through which readers perceive the events (Langacker, 1991; Van Hoek, 2007). Second, eyewitnesses are in journalistic narratives more often referred to with pronouns than nouns, whereas non-eyewitnesses are more often referred to with nouns than pronouns. This indicates that the eyewitnesses are cognitively highly accessible and that the events are related through their viewpoints (Ariel, 1988; Gundel et al., 1993; Van Hoek, 2003, 2007). Moreover, by using pronouns rather than nouns to refer to eyewitnesses, journalists increase the conceptual proximity between their own viewpoints, the eyewitnesses' viewpoints, and the readers' viewpoints (Van Hoek, 2007). Similarly, by using nouns rather than pronouns to refer to non-eyewitnesses, journalists distance themselves (and hence the readers) from the viewpoints of non-eyewitnesses.

\section{Discussion}

These results lead to the question as to what extent the use of grammar and reference in journalistic narratives facilitates readers' experience of becoming a mediated witness to shocking criminal acts. A mediated witness experience consists of two dimensions: empathy with eyewitnesses to a crime and the virtual experience of that crime from up close (Peelo, 2006). Although both subject choice and pronoun use are likely to contribute to a mediated witness experience, their impact on the respective components might differ. As for the first dimension, empathy with eyewitnesses, choice of subject is particularly important as a subject "tends to be a locus of empathy or point of view, in the sense that speakers sometimes view the imagined scene through the eyes of the subject" (Van Hoek, 2007: 900). Accordingly, a protagonist who fulfills the role of grammatical subject can be seen as the reader's gateway to narrative events; it is through this protagonist's perspective that the reader perceives the events. It is perhaps not surprisingly, then, that readers empathize more strongly with eyewitnesses to news events if the events are described from these persons' perspectives (Van Krieken et al., submitted for publication-b). The predominant use of eyewitnesses as grammatical subject in news narratives is therefore likely to evoke readers' empathy with eyewitnesses.

\footnotetext{
${ }^{6}$ Although this might at first glance seem to contradict hypothesis 1 , it is on second thought evident that perpetrators must be most prominent on the level of individual protagonists: It is they who caused the newsworthy events and are in that sense the most important news actors. Thus, it is even more noteworthy that journalists would describe the events from the viewpoints of several eyewitnesses (instead of one) and deliberately increase the prominence of eyewitnesses by placing them - overall - most often in subject position.
} 
As for the virtual observation of a crime from up close, the second dimension of a mediated witness experience, pronoun use can be considered an important factor. When reading a narrative and mentally simulating the narrative events and protagonists' actions, readers either take an observer or a field position (Boyd, 2009: 157-158). Readers who take an observer position look at the events "from the outside"; they perceive the events and protagonists from an external perspective as if they were watching a game. Readers who take a field position look at the events "from the inside"; they perceive the events from the internal perspective of a protagonist as if they had a part in the game at the playing field (cf. Nigro and Neisser, 1983). Similarly, Oatley (1999) distinguishes between spectatorship (i.e., the reader is present in the story world as an unobserved observer) and identification (i.e., the reader is present in the story world and observes the events from the perspective of a character) as two types of reading experiences.

Experimental research has shown that pronouns play a pivotal role in the position people take when reading a narrative: they tend to take an internal field position when protagonists are referred to with the second person pronoun you, but to take an external observer position when protagonists are referred to with the first person pronoun $/$ or the third person pronoun he (Brunyé et al., 2009; Ditman et al., 2010). In addition, readers are most likely to simulate a protagonist's emotions when that protagonist is referred to with you (Brunyé et al., 2011). These findings suggest that second person pronouns would be more successful in eliciting a mediated witness experience than first person or third person pronouns. However, within the genre of journalism, the use of pronouns is rather inflexible. The use of a second person pronoun to refer to a person involved in a news event would falsely imply that the addressee (i.e., the reader) is that person, while the use of a first person pronoun to refer to a person involved would falsely imply that the journalist himself is that person. Hence, for journalists, choosing a referential expression most often means choosing between a third person pronoun and a noun.

However, as Sanford and Emmott (2012: 165-166) remark, there are more linguistic strategies than the use of second person pronouns that might prompt an internal perspective. They describe how verbs of perception, detailed descriptions, deictic expressions, and thought representations can put readers in a field position as well, even in a third person narration. The results of the present study implicate that in news narratives, journalists use pronouns to refer to eyewitnesses and nouns to refer to non-eyewitnesses as an alternative strategy to draw the reader close to eyewitnesses to shocking news events. The use of referential expressions can thus be seen as an important facilitator of a mediated witness experience within the boundaries set by the genre: It encourages the reader to take an internal field position and to virtually observe the news events from up close, while reassuring that the journalist is reporting these events and perceptions from the outside.

Interesting in this respect is the final sentence of excerpt 2, taken from a journalistic narrative: "She wondered: How do you explain unimaginable horror to the most innocent?" This example provides a complex interplay of multiple viewpoints; the construction itself represents both the journalist's and the eyewitness's viewpoints, and the second person pronoun refers to the eyewitness's viewpoint as well as to a generic viewpoint. Importantly, the use of a second person pronoun does not violate journalistic conventions because the reference to the eyewitness is made by the eyewitness herself. The journalist strategically embeds the viewpoint of the eyewitness into his own viewpoint and allows her to appeal to the viewpoint of the reader by the use of a second person pronoun. This is in line with the finding that in present-day journalism, linguistic elements that express a certain degree of subjectivity, including second person pronouns, are mainly used in stretches of discourse that can be attributed to sources (Vis et al., 2012). The construction with you can thus be seen as an inventive technique that encourages the reader to (temporarily) take an internal field position and to simulate being in the position of the eyewitness during the attack, without disregarding journalism's demand of factuality. Observations like this ask for additional, in-depth analyses of pronoun use in journalistic narratives to disclose the full range of techniques journalists employ, within clear genre boundaries of legitimacy and transparency, to increase the proximity between their own viewpoints, eyewitnesses' viewpoints, and readers' viewpoints. In addition, experimental studies assessing the actual impact of pronouns and grammatical roles would substantially advance our understanding of how they put readers in the position of a mediated witness.

In sum, the present study shows that journalists strategically use grammar and reference in news narratives to describe shocking news events from the viewpoints of eyewitnesses. Note that referential expressions are not the only linguistic strategies that journalists have at their disposal to describe news events from the viewpoints of eyewitnesses and to elicit empathy. Among the list of linguistic elements that add to the representation of viewpoint are adverbs, demonstratives, negations, prepositions, and connectives (e.g., Dancygier, 2012b; Fillmore, 1997; Langacker, 2008; Sanders et al., 2012). Regarding the elicitation of reader's empathy, the use of adjectives, reflexives, and reciprocal verbs might play a role as well (Kuno, 1987). In addition, Hartley (1982: 90-94) discusses how the labeling of news sources as members of a family offers the audience a potential point of identification with these sources. Future studies on viewpoint representation could examine the use of these and other strategies in news narratives. Such studies are important to attain a comprehensive view on the way language is used in these narratives to allow the audience to understand what those who have been affected by shocking events have gone through. 


\section{Appendix A. Pairwise comparisons using the Marascuilo procedure}

Critical ranges for the Marascuilo procedure are calculated as follows (where $p$ is proportion and $n$ is sample size):

$$
\text { Critical range }=\sqrt{\chi_{U}^{2}} \sqrt{\frac{p_{j}\left(1-p_{j}\right)}{n_{j}}+\frac{p_{j^{\prime}}\left(1-p_{j^{\prime}}\right)}{n_{j^{\prime}}}}
$$

The critical ranges for the pairwise comparisons between eyewitnesses and non-eyewitnesses are listed in the table below. A difference between two proportions is statistically significant if its absolute value exceeds the critical range value (Table A1).

Table A1

Pairwise comparisons for protagonists in subject position in news narratives.

\begin{tabular}{llll}
\hline Comparison & Absolute difference $\left(p_{1}-p_{2} ; p_{1}-p_{3} \ldots\right)$ & Critical range & Significant \\
\hline Eyewitnesses $>$ victims & 0.359 & 0.094 & Yes \\
Eyewitnesses $>$ perpetrator & 0.272 & 0.102 & Yes \\
Eyewitnesses $>$ police & 0.391 & 0.090 & Yes \\
Eyewitnesses $>$ authorities & 0.444 & 0.084 & Yes \\
Eyewitnesses $>$ others & 0.361 & 0.094 & Yes \\
\hline
\end{tabular}

\section{References}

Ariel, Mira, 1988. Referring and accessibility. Journal of Linguistics 24, 65-87.

Ariel, Mira, 1990. Accessing Noun-phrase Antecedents. Routledge, New York.

Bell, Allan, 1991. The Language of News Media. Blackwell, Oxford.

Boyd, Brian, 2009. On the Origin of Stories: Evolution, Cognition and Fiction. Harvard University Press, Harvard.

Brunyé, Tad T., Ditman, Tali, Mahoney, Caroline R., Augustyn, Jason S., Taylor, Holly A., 2009. When you and I share perspectives: Pronouns modulate perspective taking during narrative comprehension. Psychological Science 20, 27-32.

Brunyé, Tad T., Ditman, Tali, Mahoney, Caroline R., Taylor, Holly A., 2011. Better you than I: Perspectives and emotion simulation during narrative comprehension. Journal of Cognitive Psychology 23, 659-666.

Clancy, Patricia M., 1980. Referential choice in English and Japanese narrative discourse. In: Chafe, W.L. (Ed.), The Pear Stories: Cognitive, Cultural, and Linguistic Aspects of Narrative Production. Ablex, Norwood, NJ, pp. 127-201.

Dancygier, Barbara, 2012a. The Language of Stories: A Cognitive Approach. Cambridge University Press, Cambridge.

Dancygier, Barbara, 2012b. Negation, stance verbs and intersubjectivity. In: Dancygier, B., Sweetser, E. (Eds.), Viewpoint in Language: A Multimodal Perspective. Cambridge University Press, Cambridge, pp. 69-96.

Ditman, Tali, Brunyé, Tad T., Mahoney, Caroline R., Taylor, Holly A., 2010. Simulating an enactment effect: Pronouns guide action simulation during narrative comprehension. Cognition 115, 172-178.

Fillmore, Charles J., 1997. Lectures on Deixis. CSLI Publications Stanford, CA, USA.

Fox, Barbara A., 1987. Discourse Structure and Anaphora: Written and Conversational English. Cambridge University Press, Cambridge.

Gundel, Jeanette K., Hedberg, Nancy, Zacharski, Ron, 1993. Cognitive status and the form of referring expressions in discourse. Language 69, 274-307.

Hartley, John, 1982. Understanding News. Methuen, London.

Hartsock, John C., 2007. "It was a dark and stormy night": Newspaper reporters rediscover the art of narrative literary journalism and their own epistemological heritage. Prose Studies 29, 257-284.

Hendriks, Petra, de Hoop, Helen, de Swart, Henriëtte, 2012. The interplay between the speaker's and the hearer's perspective. Journal of Logic, Language and Information 21, 1-5.

Johnston, Jane, Graham, Caroline, 2012. The new, old journalism. Journalism Studies 13, 517-533.

Kitch, Carolyn, 2009. Tears and trauma in the news. In: Zelizer, B. (Ed.), The Changing Faces of Journalism: Tabloidization, Technology and Truthiness. Routledge, New York, pp. 29-40.

Kuno, Susumu, 1987. Functional Syntax: Anaphora, Discourse and Empathy. University of Chicago Press, Chicago.

Langacker, Ronald W., 1987. Foundations of Cognitive Grammar, Vol. I: Theoretical Prerequisites. Stanford University Press, Stanford.

Langacker, Ronald W., 1991. Foundations of Cognitive Grammar, Vol. II: Descriptive Application. Stanford University Press, Stanford.

Langacker, Ronald W., 2008. Cognitive Grammar: A Basic Introduction. Oxford University Press, Oxford.

Marascuilo, Leonard A., 1966. Large-sample multiple comparisons. Psychological Bulletin 65, 280-290.

Martin, James R., Rose, David, 2003. Working With Discourse: Meaning Beyond the Clause. Continuum, London.

Martin, James R., White, Peter R.R., 2005. The Language of Evaluation: Appraisal in English. Palgrave/Macmillan, London/New York.

Nigro, Georgia, Neisser, Ulric, 1983. Point of view in personal memories. Cognitive Psychology 15, 467-482.

Oatley, Keith, 1999. Meetings of minds: Dialogue, sympathy, and identification, in reading fiction. Poetics 26, 439-454. 
Peelo, Moira, 2006. Framing homicide narratives in newspapers: Mediated witness and the construction of virtual victimhood. Crime, Media, Culture 2, 159-175.

Sanders, José, 2010. Intertwined voices: Journalists' modes of representing source information in journalistic subgenres. English Text Construction 3, 226-249.

Sanders, José, Redeker, Gisela, 1993. Linguistic perspective in short news stories. Poetics 22, 69-87.

Sanders, José, Sanders, Ted, Sweetser, Eve, 2012. Responsible subjects and discourse causality: How mental spaces and perspective help identifying subjectivity in Dutch backward causal connectives. Journal of Pragmatics 44, 191-213.

Sanford, Anthony J., Emmott, Catherine, 2012. Mind, Brain and Narrative. Cambridge University Press, Cambridge.

Schudson, M., 2001. The objectivity norm in American journalism. Journalism 2, 149-170.

Stenvall, Maija, 2008. On emotions and the journalistic ideals of factuality and objectivity-Tools for analysis. Journal of Pragmatics 40, 15691586.

Van Hoek, Karen, 1997. Anaphora and Conceptual Structure. University of Chicago Press, Chicago, IL.

Van Hoek, Karen, 2003. Pronouns and point of view: Cognitive principles of coreference. In: Tomasello, M. (Ed.), The New Psychology of Language: Cognitive and Functional Approaches to Language Structure. Lawrence Erlbaum, Mahwah, NJ, pp. $169-194$.

Van Hoek, Karen, 2007. Pronominal anaphora. In: Geeraerts, D., Cuyckens, H. (Eds.), The Oxford Handbook of Cognitive Linguistics. Oxford University Press, Oxford, pp. 890-916.

Van Krieken, Kobie, Sanders, José, Hoeken, Hans, under review-a. Blended viewpoints, mediated witnesses: A cognitive-linguistic approach to news narratives.

Van Krieken, Kobie, Hoeken, Hans, Sanders, José, under review-b. From reader to mediated witness: The engaging effects of journalistic crime narratives.

Vandelanotte, Lieven, 2004. From representational to scopal 'distancing indirect speech or thought': A cline of subjectification. Text 24, 547-585.

Vis, Kirsten, Sanders, José, Spooren, Wilbert, 2012. Diachronic changes in subjectivity and stance-A corpus linguistic study of Dutch news texts. Discourse, Context \& Media 1, 95-102.

Wahl-Jorgensen, Karin, 2013a. The strategic ritual of emotionality: A case study of Pulitzer Prize-winning articles. Journalism 14, $129-145$.

Wahl-Jorgensen, Karin, 2013b. Subjectivity and story-telling in journalism. Journalism Studies 14, 305-320.

Wardle, Claire, 2006. "It could happen to you": The move towards "personal" and "societal" narratives in newspaper coverage of child murder, 1930-2000. Journalism Studies 7, 515-533.

Ytreberg, Espen, 2001. Moving out of the inverted pyramid: Narratives and descriptions in television news. Journalism Studies 2, 357-371.

\section{Further reading}

The Associated Press, 2007, April 16. "Gunman kills 21 at Virginia Tech shooting before being killed." Lindsey, Sue.

The Associated Press, 2012, July 20. "Police: 12 dead in Colorado theater shooting." Peipert, Thomas.

The Associated Press, 2012, December 15. "Gunman kills 26 at Conn. school, commits suicide." Christoffersen, John.

The Washington Post, 2007, April 19, p. A01. "That Was the Desk I Chose to Die Under." Maraniss, David.

The Washington Post, 2012, July 21, p. A07. "Gunman opens fire at Colorado movie theater, killing 12." Fahrenthold, David, Horwitz, Sari, Turque, Bill.

The Washington Post, 2012, December 16, p. A01. "Seeking calm amid the terror." Saslow, Eli.

Algemeen Nederlands Persbureau, 2011, April 9. "Doden en gewonden bij schietpartij Alphen." [Dead and wounded at shooting Alphen.] Kind Deligt, Wendy.

Algemeen Nederlands Persbureau, 2009, April 30. "Dramatische Koninginnedag in Apeldoorn." [Dramatic Queen's Day in Apeldoorn.] Halkema. NRC Handelsblad, 2011, April 11, p. 04 "Bij de groenteafdeling ligt een man. Hij bloedt uit zijn zij." [In the vegetable aisle lies a man. He is bleeding from his side.] Funnekotter, Bart, Mat, Joke.

NRC Handelsblad, 2009, April 30, p. 03. "Een groot aantal gewonden en onwezenlijke rust; Automobilist die bij viering Koninginnedag in Apeldoorn met zijn auto door haag toeschouwers en dranghekken reed geef gas." [Large number of wounded and unreal serenity; Driver who drove with his car through hedge of spectators during celebration Queen's Day accellerated.]. 